\title{
Les lampes anciennes
}

\author{
Bianca Côté
}

\begin{abstract}
Antique Lamps
In the city traversed here everything is paradoxically close at hand and situated at an unreachable distance. A Somalian woman, dressed as if for Halloween in an assemblage of rags. "Feed Me," her sign says. Were she to share a fragment of her life with me, I would not understand. A hollowed-out church. Through its frame, I see the city. Perhaps also the century. For something is about to begin all over again. A world? In the gay village, a poster: "By the Year 2,000, Victims of Contaminated Blood Will Have Disappeared." Flashback of a news report, Christmas morning: the Italian nun will not allow the sick to appear on television. (For her, every single victim has a face.) Back towards the city, a shopfront reads: "We care for old lamps." As long as there are antique lamp restorers, I think I can hold onto hope. My neighbourhood now. A woman smiling at her lover, another fishing for quarters in the phone boxes. I live in the city - in the midst of everything, far away from it all.
\end{abstract}

Une Somalienne tend un papier d'un air pathétique, nourrissez-moi, demande mille fois par jour son statut de réfugiée. Elle s'habille comme pour l'Halloween, réflexion d'enfant, des lambeaux reconstitués, qu'at-elle apporté de son monde, dans quel fragment se terre sa vie? Elle pourrait sûrement me donner un fragment. Mais je ne le comprendrais pas. J'entendrais les sons, les souvenirs. Pour un instant, je ne penserais pas à mes pensées.

Trottoirs brûlants. Dans le soleil, une église. Évidée, il ne reste que la charpente, c'est si beau. On voit la ville à travers elle, j'allais dire on voit le siècle, quelque chose est à recommencer. Un monde.

Le prêtre sort de l'église et s'empare du soleil à pleines mains. Un enfant s'amuse à effrayer les pigeons, plaisir mille fois renouvelable. De jeunes femmes rebelles épuisent leurs bicyclettes. D'autres, moins pressées, se délectent de boissons chinoises. Les hommes d'affaires 
s'arrêtent pour achêter des sushis. Un adolescent court pour attraper l'autobus. Lance un cri tout essoufflé.

Dans le Village gai, une affiche. D'ici l'an 2000, les victimes du sang contaminé seront disparues. Me revient un reportage, diffusé le matin de Noël à Radio-Canada. La religieuse italienne refusait que ses malades passent à la télévision. Pour elle, chaque victime a un visage. Lentement sa voix scandait: Partager, c'est prendre le cru et le cuit. Est-ce que les exils se partagent? Combien de temps peut-on survivre sans bras autour de soi, avec la soif qui certains jours nous fait disparaître un peu? Serrement de gorge puis, demi-sourire, je reviens à la ville. Sur une devanture de magasin: Nous prendrons soin de vos lampes anciennes. Tant qu'il y aura des restaurateurs de lampe ancienne, je peux recourir sans gêne au mot espoir.

Lentement, je rejoins mon quartier. Une femme sourit à son amoureux, une autre regarde au bas de chaque téléphone public si un 25 cent n'aurait pas été oublié. Des mains d'ébéniste jouent avec un moteur d'auto. À ses côtés, un Pinocchio de huit ans, impatient de construire son château de sable.

À Los Angeles, deux garçons ont fait taire pour l'éternité un bambin de deux ans. Faire taire était-il leur motif?

Je vis dans une ville, près de tout. Si loin de moi. Peut-on... s'habiter dans le vertige? 